\title{
Sistema computacional para a determinação da lâmina ótima econômica em irrigação pressurizada ${ }^{1}$
}

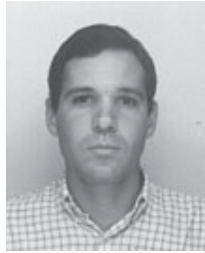

Marcelo C. Castro ${ }^{2}$, Manoel A. de Faria ${ }^{3}$ \& Antônio M. da Silva ${ }^{3}$

\begin{abstract}
1 Parte da Dissertação de Mestrado do primeiro autor apresentado a UFLA
${ }^{2}$ R. Tupis, 317, Ap. 702, Centro, CEP 30.190-060, Belo Horizonte, MG. Fone: (31) 3217-2767. E-mail: marcelo@genetic.com.br (Foto)

${ }^{3}$ UFLA, CP 37, CEP 37.200-000, Lavras, MG. Telefax: (35) 3829-1362. E-mail: pgenagri@ufla.br
\end{abstract}

Protocolo $105-2 / 7 / 2001$

\begin{abstract}
Resumo: $O$ interesse do produtor rural é a rentabilidade de sua atividade, de tal maneira que possa obter o máximo benefício com os insumos empregados. Neste processo, a irrigação tem capital importância, uma vez que permite, genericamente, elevar significativamente a produtividade e, com ela, os ganhos. Entretanto, este recurso de produção muitas vezes não é bem empregado, por falta de conhecimentos e/ou ferramentas técnico-econômicas para sua utilização. Assim, este trabalho objetivou mostrar como o sistema computacional Tobruk pode ser utilizado para o planejamento da agricultura irrigada. Para isso, exemplos de determinação da lâmina econômica ótima de irrigação e sua forma de obtenção no campo, análise da viabilidade econômica do plantio irrigado, determinação da época de plantio que proporcione maior lucro e escolha do sistema de irrigação de melhor desempenho econômico, foram utilizados.
\end{abstract}

Palavras-chave: agricultura irrigada, irrigação localizada, irrigação por aspersão

\section{Software for the determination of the optimum irrigation depth in pressurized irrigation systems}

\begin{abstract}
The main interest of a rural producer is the economic return of his activity. In this process, the irrigation has great importance as it permits a significant rise of productivity and profit. However, this is not always well applied due to the lack of knowledge and the required tools. The objective of this study is to show how the Tobruk's software could be used for the planning of the irrigated agriculture. For that, examples of determination of the optimum economical irrigation depth, and its determination in the field, analysis of the economical viability of the irrigated crop, determination of the planting date that provides higher profits and the choice of the most economical irrigation system have been shown.
\end{abstract}

Key words: irrigated agriculture, trickle irrigation, sprinkle irrigation

\section{INTRODUÇÃO}

Ao produtor rural interessa um planejamento agrícola que leve ao máximo retorno econômico de suas atividades. $\mathrm{Na}$ agricultura, ao contrário do setor industrial, os preços dos produtos, em geral, são preestabelecidos, não sendo influenciados nem controlados por aqueles que os produzem isoladamente. Há pouco tempo, o valor do produto agrícola tem registrado sucessivas quedas, enquanto os custos de produção se elevam continuamente. Neste cenário, resta ao produtor rural direcionar seu esforço para a redução de seus custos e aumento da produtividade.

A irrigação constitui alternativa para a melhoria do rendimento de grande parte das culturas, proporcionando um incremento médio de produtividade, da ordem de $200 \%$, (Gonzaga Neto, 2000) e, com isto propicia redução dos custos unitários de produção. Entretanto, apenas com um planejamento racional da agricultura irrigada, baseado em um projeto bem elaborado, adequadamente manejado e sem degradação do meio ambiente, é que os irrigantes poderão usufruir plenamente dos benefícios advindos da irrigação e se tornarem mais competitivos, em um mundo cada vez mais globalizado.

Neste sentido, Bruxel (1991) menciona que a experiência dos produtores rurais tem mostrado que nem sempre há rentabilidade na agricultura irrigada, o que evidencia uma ausência de planejamento da mesma, devido a uma carência ou falta de uso de instrumentos para tal, ou a sua elaboração e/ou execução deficiente. Com relação ao planejamento da atividade 
irrigada, o uso de programas computacionais vem auxiliar, em muito, este processo, facilitando e agilizando a tomada de decisão.

Nas últimas décadas, diversos programas computacionais foram desenvolvidos, com o propósito de auxiliar o planejamento operacional de sistemas de irrigação como aqueles apresentados por Windsor \& Chow (1971), Dean (1980), Tracy \& Marino (1989), Leme \& Chaudhry (1992) e Prajamwong et al. (1997). Tais programas diferem entre si basicamente pela linguagem de programação utilizada, grau de complexidade do algoritmo empregado, quantidade e tipo de dados requeridos e precisão obtida. Embora a ênfase dos programas ora desenvolvidos tenha sido o uso da irrigação para a obtenção da produtividade física ótima, ou máxima produção, Bernardo (1998) lembra que o aumento da produtividade não é o objetivo final, mas um caminho para se obter o máximo lucro. Desta forma, visando auxiliar o planejamento da agricultura irrigada com sistemas pressurizados, Castro (2001) desenvolveu um sistema computacional para uso por técnicos, com noções básicas em agricultura irrigada, ao qual chamou de Tobruk, objetivando a determinação da lâmina de irrigação que proporciona maior retorno econômico.

Assim, este trabalho objetiva apresentar o sistema computacional Tobruk e exemplificar como o mesmo pode ser utilizado para o planejamento técnico-econômico da agricultura irrigada, em uma propriedade específica.

\section{DESENVOLVIMENTO}

\section{Características básicas do sistema computacional Tobruk}

O sistema computacional Tobruk possui o objetivo de fornecer o valor da lâmina ótima econômica de irrigação apenas em situações que possuem uma única cultura irrigada por sistema de irrigação, em uma área fixa de valor preestabelecido pelo usuário, na qual a água não é fator limitante à produção.

O Tobruk foi desenvolvido em linguagem de programação Delphi 5.0, versão acadêmica, em ambiente Windows 95; possui cerca de 21.500 linhas de código fonte e apresenta 31 telas para a entrada de dados e apresentação dos resultados. O Tobruk possui ainda ajuda e manual "on-line", com descrição de todas as telas, operações e dados necessários à sua execução, além de um guia simplificado para sua operação.

Os dados necessários a execução do Tobruk consistem, genericamente, daqueles relacionados à cultura (especificando informações sobre o plantio, coeficientes de cultivo e função água-produção), ao local de irrigação (referente às características físicas do solo e dados agroclimatológicos de precipitação e evapotranspiração), ao sistema de irrigação e sua forma de operação (especificando o tipo de sistema, lâmina de projeto, eficiência de irrigação, turno de rega e jornada de trabalho) e aos valores econômicos do sistema de produção (especificando informações sobre os custos e receitas de produção da cultura a ser irrigada). Em sua interface, o programa oferece opções para criação, edição e importação dos arquivos de dados agroclimatológicos necessários à sua execução, bem como o salvamento e posterior edição de todos os dados técnicos e econômicos utilizados na determinação da lâmina ótima econômica.
Para a determinação da lâmina ótima econômica, o programa utiliza um processo iterativo onde simula o balanço de água no solo com diversas lâminas de irrigação e calcula a receita líquida proporcionada por tais lâminas, adotando aquela que proporciona o maior lucro como a procurada.

O fluxo geral de operações segue a seguinte ordem: 1) leitura dos dados agroclimáticos e técnicos do sistema de irrigação; 2) processamento dos dados climáticos; 3) leitura dos dados econômicos; 4) processamento técnico-econômico dos dados; 5) apresentação dos resultados.

Em seus cálculos, o programa considera a disponibilidade total de água no solo para as culturas, segundo modelo de Bernardo (1989), estimando a profundidade efetiva das raízes pela simulação de seu crescimento diário, de acordo com a metodologia de Borg \& Grimes (1986).

O balanço de água no solo, que contabiliza as entradas e saídas de água devido a evapotranspiração, precipitação, irrigação, percolação e escoamento superficial, é simulado em intervalos diários, de acordo com metodologia de Bernardo (1989).

Os valores da precipitação efetiva são estimados conforme Jensen et al. (1990). Uma vez obtidos, tais valores são ajustados pelo programa, com a finalidade de estimar o respectivo valor com uma probabilidade de ocorrência mínima de $80 \%$, por meio da função de probabilidade Gama Incompleta, segundo metodologia apresentada por Costa (1991), e funções Exponencial e Log-Normal, conforme Haan (1977). Tratando-se de precipitação, como existe a possibilidade de ocorrência de fenômenos nulos, o programa adota uma função mista, apresentada por Haan (1977), que leva em consideração a probabilidade de ocorrência de tais valores. Como existe a possibilidade de ajuste de três funções distintas para o mesmo agrupamento de dados, a escolha da melhor função é feita pelo programa com base no teste de Kolmogorov-Smirnov.

Para o cálculo da evapotranspiração da cultura de referência (ETo) o programa permite que este seja efetuado pelos métodos de Blaney-Criddle e tanque Classe A, segundo Bernardo (1989), Penman e Método da Radiação, conforme Doorenbos \& Kassam (1994), Thornthwaite, segundo Silva \& Reis (1988) e Penman-Monteith, de conformidade com Pereira \& Allen (1999).

Posteriormente ao cálculo da ETo, os resultados são agrupados dentro de intervalos predefinidos e o programa calcula a evapotranspiração da cultura de referência com uma probabilidade de ocorrência máxima de $80 \%$. Os métodos utilizados para isso são os mesmos empregados para o cálculo da precipitação provável, embora seja esperado um ajuste melhor com a distribuição normal, como obtido por Pruitt et al. (1972), ou log-normal, como conseguido por McGuiness \& Parmele (1972). A escolha da melhor função, entretanto, é feita pelo programa com base no teste de Kolmogorov-Smirnov.

Para o cálculo da evapotranspiração real da cultura (ETRc) o programa utiliza a Eq. 1, na qual, caso o sistema de irrigação seja por aspersão, o programa assume que o coeficiente de localização (KL) e o coeficiente de advecção (Ka) são iguais a unidade $(\mathrm{KL}=\mathrm{Ka}=1)$. No caso de irrigação localizada, o valor do coeficiente de advecção é determinado segundo metodologia apresentada por Cabello (1990) e, com relação ao 
valor do coeficiente de localização, o programa oferece quatro opções para a sua determinação relativas às metodologias de Aljibury, Decroix, Hoare e Keller, fornecidas também por Cabello (1990), devendo o usuário escolher uma delas.

$$
\mathrm{ETRc}=\mathrm{K} \mathrm{Kc} \mathrm{KL} \mathrm{Ka} \mathrm{ETo}
$$

em que:

ETRc - evapotranspiração real da cultura, $\mathrm{mm} \mathrm{d}^{-1}$

K - coeficiente de umidade do solo, calculado segundo Bernardo (1989), adimensional

Kc - coeficiente da cultura no dia em questão, adimensional

KL - coeficiente de localização, adimensional

$\mathrm{Ka}$ - coeficiente de advecção, adimensional

ETo - evapotranspiração provável de referência, $\mathrm{mm} \mathrm{d}^{-1}$

A lâmina líquida de irrigação é determinada com base em algum valor porcentual da evapotranspiração, relativo ao período do turno de rega em questão, variando entre um limite superior, predefinido pelo usuário, e um inferior, estabelecido pelo programa em $1 \%$ da evapotranspiração do período, sendo seu valor efetivo, entretanto, limitado ao máximo necessário para elevar a umidade atual do solo à capacidade de campo.

Para a determinação da lâmina bruta de irrigação, o programa utiliza as metodologias apresentadas por Keller \& Bliesner (1990) e Cabello (1990), respectivamente, para os casos de irrigação por aspersão e localizada.

Para cada valor de lâmina bruta total de irrigação, a receita líquida (lucro) é determinada pela diferença entre a receita bruta, calculada pela Eq. 2, e o somatório dos custos fixos e variáveis totais. O custo fixo total é determinado pelo somatório dos seguintes custos: depreciação do equipamento de irrigação, calculada pela metodologia de Tomazela \& Scaloppi (1988); demanda de energia elétrica; administração direta e mãode-obra fixas; seguro do equipamento; manutenção de componentes do sistema de irrigação; tarifa pública de água; outros custos fixos que o usuário queira incluir. Já o custo variável total consiste no somatório dos seguintes custos: despesas com energia ou combustível consumido pelo(s) motor(es) do sistema de irrigação; mão-de-obra temporária; fertilizantes e defensivos utilizados na produção e sua aplicação; despesas referentes à colheita, secagem e transporte da produção; outros custos variáveis que o usuário queira utilizar.

$$
\mathrm{RT}=\mathrm{PRD} \text { Py AI }
$$

em que:

RT - receita bruta total, $\mathrm{R} \$$

PRD - produtividade obtida com a lâmina total, correspondente a precipitação e irrigação, usando-se a função água-produção da cultura em questão, $\mathrm{kg} \mathrm{ha}^{-1}$

Py - valor unitário da produção, $\mathrm{R} \$ \mathrm{~kg}^{-1}$

AI - área total irrigada, ha

$\mathrm{Na}$ apresentação dos resultados, além de mostrar o valor da lâmina ótima econômica de irrigação e o lucro por ela proporcionado, o programa mostra também o valor de reposição da evapotranspiração a que se refere tal lâmina, a fim de orientar, em termos gerais, o manejo da irrigação para sua obtenção. O programa apresenta, ainda, em caráter complementar, gráficos e planilhas com informações técnicas e econômicas utilizadas no processo de obtenção da lâmina ótima econômica, bem como o balanço hídrico para a condição ótima econômica, permitindo sua impressão ou gravação para arquivo em disco. Pode-se, ainda, ajustar uma equação que descreva a relação entre as lâminas de irrigação simuladas e os respectivos lucros esperados para a situação técnica-econômica específica da análise.

O sistema computacional Tobruk pode ser obtido por meio dos endereços: pgenagri@ufla.br e marcelo@genetic.com.br.

\section{APLICAÇÃO}

\section{Dados utilizados nos exemplos de aplicação}

Para exemplificar a utilização do Tobruk, obtiveram-se os dados de um local irrigado através do sistema pivô central, com área de 30,55 ha, em Três Pontas, MG. O solo sob irrigação apresentou os valores de umidade na capacidade de campo e no ponto de murcha permanente, respectivamente de 34 e $22 \%$, em base peso, e massa específica global de $1,2 \mathrm{~kg} \mathrm{dm}^{-3}$. Utilizaram-se os dados meteorológicos obtidos da estação climatológica principal de Lavras, MG, situada no Campus da Universidade Federal de Lavras (UFLA) referentes ao período de 1989 a 2000. Tais dados consistiam-se nos valores diários de precipitação, evaporação do tanque Classe $\mathrm{A}$, velocidade média do vento e umidade relativa média. A cultura utilizada nas simulações foi a do feijoeiro, estudada por Felipe (1991), plantada no Campus da UFLA em 4 de abril, cuja função água-produção (FAP) apresentada na Eq. 3, possui limites de validade entre 169 e $283 \mathrm{~mm}$. Uma vez que o programa só admite valores fixos de turno de rega, o mesmo foi estabelecido em cinco dias, conforme projeto técnico elaborado para o pivô central da referida propriedade, satisfazendo, inclusive, as condições de geração da FAP. Nas simulações, consideraram-se os valores dos coeficientes da cultura, sugeridos por Doorenbos \& Kassam (1994) os quais estão disponíveis no programa. Com relação aos parâmetros econômicos, utilizouse o orçamento atualizado do sistema de irrigação instalado conforme apresentado na Tabela 1, no qual se utiliza motor a óleo diesel para o acionamento da bomba de irrigação. Pelo projeto técnico, a lâmina líquida é $6,8 \mathrm{~mm} \mathrm{~d}^{-1} \mathrm{e}$ a lâmina bruta de $8,0 \mathrm{~mm} \mathrm{~d}^{-1} \mathrm{em}$ um tempo de trabalho diário de $24 \mathrm{~h}$, exigindo uma potência líquida do motor de $42,47 \mathrm{~kW}$.

Tabela 1. Orçamento simplificado do sistema de irrigação por pivô central

\begin{tabular}{lr}
\hline Item & Valor $(\mathrm{R} \$)$ \\
\hline Conjunto motobomba & $23.470,00$ \\
Tubulação adutora e acessórios & $8.965,00$ \\
Parte aérea do pivô & $66.310,00$ \\
Diversos (cabos elétricos, gerador) & $16.812,00$ \\
Total & $115.557,00$ \\
\hline Fonte: Lavras Irrigação, fevereiro de 2001 &
\end{tabular}




$$
\mathrm{Y}=-0,067588 \mathrm{~W}^{2}+42,3725 \mathrm{~W}-5064,8170
$$

em que:

$$
\begin{array}{ll}
\mathrm{Y} & \text { - produtividade, } \mathrm{kg} \mathrm{ha}^{-1} \\
\mathrm{~W} & \text { - lâmina total aplicada, } \mathrm{mm}
\end{array}
$$

Os custos de produção da cultura do feijoeiro se basearam nos valores médios fornecidos por Du Pont (2000) para uma produtividade de $1600 \mathrm{~kg} \mathrm{ha}^{-1}$, conforme apresentado na Tabela 2, considerando-se ainda uma equivalência de US\$1,00= $\mathrm{R} \$ 2,00$. Esta produtividade é a que mais se aproxima do valor máximo possível de ser obtido pela função água-produção utilizada, de $1576 \mathrm{~kg} \mathrm{ha}^{-1}$. A receita bruta considerada foi de $\mathrm{R} \$ 80,00 \mathrm{saca}^{-1}$. Considerou-se, ainda, o valor do óleo diesel de $\mathrm{R} \$ 0,809 \mathrm{~L}^{-1}$ e o custo da mão de obra exclusivamente para a operação do pivô de R\$250,00 mês $^{-1}$. Arbitrou-se a taxa de juros anual em $12 \%$ e o tempo de utilização do sistema de irrigação, em $210 \mathrm{~d} \mathrm{ano}^{-1}$.

Tabela 2. Valores médios do custo de produção do feijão para uma produtividade de $1600 \mathrm{~kg} \mathrm{ha}^{-1}$

\begin{tabular}{lc}
\hline Item & Valor $\left(\mathrm{R} \$\right.$ ha $\left.^{-1}\right)$ \\
\hline Custo de implantação & 184,68 \\
Custos com adubação e defensivos & 439,76 \\
Custo de colheita e transporte da produção & 220,80 \\
Custos diversos & 192,00 \\
\hline
\end{tabular}

Fonte: Du Pont (2000)

Com base nesses dados e se utilizando o sistema computacional Tobruk, determinou-se a lâmina ótima econômica de irrigação e a maneira de sua obtenção, verificou-se a viabilidade econômica do plantio de feijão irrigado, estimou-se a melhor época de plantio do mesmo e se comparou, economicamente, o sistema de irrigação implantado com uma outra alternativa técnica para a execução da irrigação, na área em questão.

\section{Determinação da lâmina ótima econômica de irrigação}

Fornecendo-se ao programa os dados já mencionados, obteve-se a lâmina ótima econômica total de 282,99 mm, considerando-se a limitação original da função água-produção (FAP) em 283 mm. A lâmina assim encontrada compõe-se exclusivamente da irrigação, uma vez que a precipitação estimada para todo o período do ciclo da cultura foi nula. A lâmina ótima econômica de irrigação correspondeu a uma reposição de $93,03 \%$ da ETo e propiciou um lucro total de $\mathrm{R} \$ 16.103,32$. Pelo programa, obteve-se a Eq. 4, que descreve 47 relações entre a lâmina de irrigação aplicada, para valores compreendidos entre 173 e $283 \mathrm{~mm}$, e o respectivo lucro esperado, com base nos valores econômicos considerados e válida somente para o caso analisado.

$$
\mathrm{LCE}=-2,3718 \mathrm{LIA}^{2}+1458,9003 \mathrm{LIA}-206804,96\left(\mathrm{R}^{2}=0,99\right)
$$

em que:

LCE - lucro esperado, R\$

LIA - lâmina total de irrigação aplicada, mm
Observa-se que a lâmina ótima econômica de irrigação obtida é praticamente a mesma definida para o limite superior de restrição da FAP, a qual foi informada ao programa, indicando que tal restrição limita, provavelmente, o valor da lâmina ótima. Executando-se novamente o programa e se ignorando os limites da FAP, encontrou-se a lâmina ótima econômica de 302,34 mm, que fornece um lucro de $\mathrm{R} \$ 17.468,38$; assim, caso experimentos comprovem a validade desta FAP para lâminas iguais ou superiores a 302,34 mm e as considerações econômicas utilizadas permaneçam as mesmas, dever-se-ia adotar, teoricamente, este valor de lâmina para o manejo do sistema. Deve-se observar que a lâmina assim encontrada $(302,34 \mathrm{~mm})$ difere daquela que maximiza o lucro esperado fornecido pela Eq. 4 (307,55 mm), uma vez que as condições encontradas na simulação diferem daquelas da extrapolação dos resultados da Eq. 4.

A máxima produção física da FAP utilizada, dada pela Eq. 3, é obtida com a lâmina de $313,46 \mathrm{~mm}$. Substituindo-se este valor na Eq. 4, estima-se um lucro de $\mathrm{R} \$ 17.455,57$, o qual é $0,07 \%$ inferior ao máximo econômico, para um acréscimo de lâmina de $3,69 \%$ em relação à ótima econômica; desta forma, em termos práticos, poder-se-ia adotar o manejo de irrigação para a obtenção da máxima produção física sem grandes prejuízos, caso se considere a FAP válida para esta situação.

Bernardo (1998) menciona que um problema comum no Brasil é a baixa eficiência com que a irrigação é executada. Uma vez que o Tobruk preconiza o uso racional da água de irrigação, pode-se esperar que o programa venha a ser uma "ferramenta" auxiliar no combate a este problema, proporcionando redução dos impactos indesejáveis causados pela agricultura irrigada ao meio ambiente.

\section{Análise da viabilidade econômica do plantio irrigado}

Uma situação relevante é se definir o valor da receita bruta a partir do qual a irrigação se viabiliza. Com os dados do pivô central e considerações já mencionadas, executou-se o programa várias vezes, alterando-se apenas o valor de venda do feijão (receita bruta) e se obteve o respectivo lucro ótimo, os quais são apresentados na Figura 1, na qual se observa que o ponto de equivalência entre os custos e receitas (lucro nulo) é obtido para valores de $\mathrm{R} \$ 58,25$ e 57,23 $\mathrm{saco}^{-1}$, quando se consideram, respectivamente, os limites ou não da FAP. Em

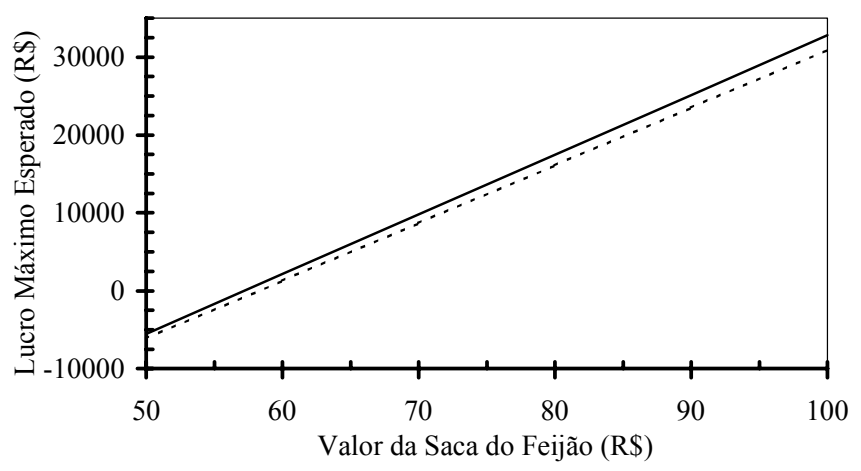

- - - Valores com restrição da FAP — Valores sem restrição da FAP

Figura 1. Valores do lucro ótimo em função do preço da saca do feijão 
outras palavras, no presente caso somente com valores previstos a partir desses preços é que se deve proceder à irrigação.

Os valores de R $\$ 58,25$ e $57,23 \mathrm{saco}^{-1}$ referem-se, respectivamente, às lâminas de 282,99 e 302,34 mm, sendo que tais lâminas se mantêm inalteradas para valores variando entre $R \$ 50,00 \mathrm{e}$ $200,00 \mathrm{saco}^{-1}$, conforme simulações efetuadas; assim, nota-se que o valor da receita bruta (preço de venda do feijão) não tem influência sobre a determinação do valor da lâmina ótima econômica para as considerações efetuadas, o que pode ser atribuído ao fato de que a lâmina ótima econômica, na condição sem restrição da FAP, corresponde à lâmina máxima que o solo suporta, no volume de controle, com a reposição ótima sempre elevando o teor de umidade à capacidade de campo. Respeitando-se os limites da FAP, o valor encontrado da lâmina ótima econômica se mantém próximo ao limite superior desta restrição, para a mesma variação no preço da saca de feijão, indicando tendência a se buscar o valor da lâmina sem a referida restrição.

A produtividade da cultura influencia diretamente a receita bruta obtida. No presente estudo, deve-se observar que a produtividade máxima da cultura, cuja FAP foi utilizada nos exemplos, é baixa quando comparada com a média das lavouras irrigadas de feijão, respectivamente de 1576 e $2200 \mathrm{~kg} \mathrm{ha}^{-1}$, segundo Du Pont (2000); desta forma, necessita-se ter um preço maior da saca do feijão para se obter um lucro nulo (ponto de equivalência entre custos e receita) com o uso da FAP ora utilizada, quando comparada com uma outra FAP que proporcione melhor produtividade como, por exemplo, em torno do valor médio de $2200 \mathrm{~kg} \mathrm{ha}^{-1}$; então, pode-se dizer que a cultura utilizada no presente exemplo só é economicamente viável para valores de venda do feijão relativamente elevados, devendo ser substituída por outra de melhor produtividade, no caso de menores valores de venda.

\section{Escolha da cultura irrigada a ser implantada}

De maneira análoga a executada anteriormente, pode-se obter o máximo retorno econômico esperado com o plantio irrigado de diversas culturas em uma mesma época, sob um mesmo sistema de irrigação pressurizado existente, desde que se tenha os parâmetros técnico-econômicos para se fornecer ao programa e, após comparar os resultados, implantar efetivamente aquela cultura que proporcione o melhor retorno econômico esperado.

Uma vez que esse tipo de análise auxilia os produtores rurais, fornecendo-lhes subsídios para a prática econômica da agricultura irrigada, espera-se que o Tobruk venha a ajudar efetivamente os produtores irrigantes que, quase sempre, não consigam obter lucro com suas atividades, em uma condição "normal" de mercado, como aqueles mencionados por Bruxel (1991).

Operacionalmente, a obtenção da estimativa do máximo lucro propor-cionado por uma cultura irrigada leva em torno de 15 min com o uso do sistema computacional Tobruk, desde que os arquivos agroclimáticos já existam e o usuário tenha experiência no uso deste programa. No caso da análise de alternativas de culturas possíveis de serem implantadas em uma mesma área, época e sistema de irrigação, considerando-se o aproveitamento das informações prévias fornecidas ao programa, relativas a obtenção da lâmina ótima econômica para dada cultura, e execução das devidas alterações para uma outra cultura, este mesmo usuário levaria em torno de 10 min para a obtenção do lucro máximo, desde que tivesse em mãos os dados a serem alterados.

\section{Determinação da melhor época de plantio}

Com base no fato de que a quantidade total de água consumida por uma cultura varia de acordo com a época de plantio, como demonstrado por Costa (1991), pode-se utilizar o sistema computacional Tobruk para procurar uma data de plantio que proporcione uma lâmina de irrigação tal, que se obtenha lucro maior que em outras datas. Obteve-se para o feijão, uma lâmina econômica ótima de 282,99 mm, referente à reposição de 93,03\% da ETo do período, para uma data de plantio em 4 de abril, que corresponde a uma produção total de 46237 kg. Com a utilização do sistema computacional Tobruk, determinou-se a lâmina econômica ótima e o respectivo lucro para plantios efetuados entre os dias 1 e 21 de abril, conforme apresentado nas Figuras 2 e 3, estabelecendo-se, como referência, irrigações baseadas na reposição de $93,03 \%$ da ETo e a produção total em $46237 \mathrm{~kg}$. Convém mencionar que todos os resultados de lâminas ótimas assim obtidas, referem-se exclusivamente a lâmina de irrigação, uma vez que a precipitação esperada durante todo o ciclo da cultura, plantada em qualquer data do intervalo analisado, sempre foi nula.

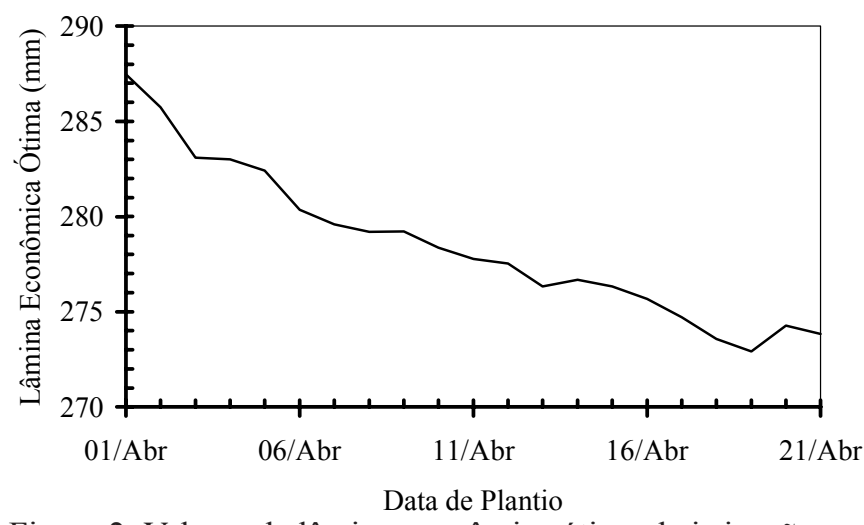

Figura 2. Valores de lâmina econômica ótima de irrigação em função da data de plantio do feijoeiro irrigado por pivô central

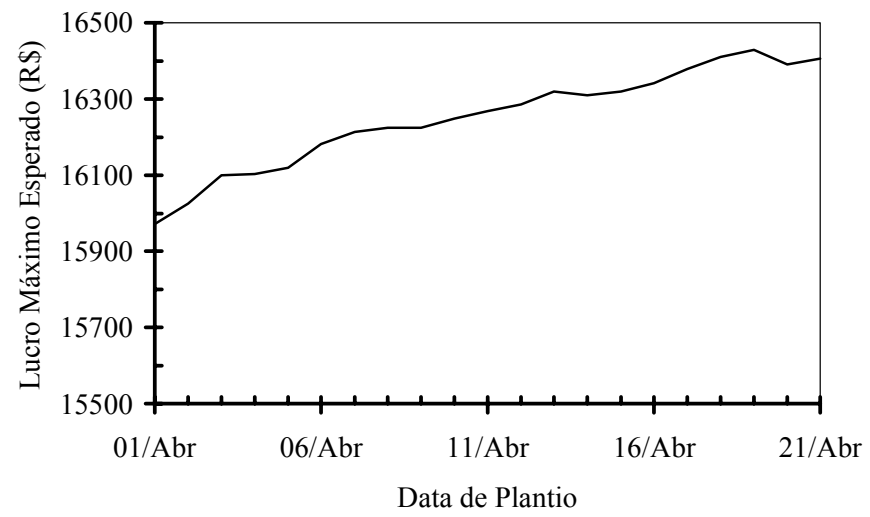

Figura 3. Valores do lucro máximo esperado em função da data de plantio do feijoeiro irrigado por pivô central 
Pela Figura 2, observa-se que a lâmina de irrigação tende a decrescer do início para o fim do período analisado. Considerando-se que a produção gerada pela cultura é a mesma em todas as datas de plantio mostradas na Figura 2, concluiuse então que, quanto menor for a lâmina de irrigação, menores serão os custos que dependem diretamente dela, como energia e mão-de-obra e, conseqüentemente, maior será o lucro, como observado na Figura 3.

Desta forma, a melhor data de plantio se refere àquela que apresenta a menor lâmina de irrigação comparada à ótima econômica da data de referência do dia 4, no caso dia 19; assim, para as condições arbitradas, espera-se que a receita seja maximizada com o plantio efetuado na terceira semana do mês de abril, considerando-se que o preço de venda do feijão seja constante ao longo do ano. Caso se tenha em mãos valores diferenciados do produto ao longo do ano, os mesmos podem ser fornecidos ao programa, para a obtenção de resultados mais confiáveis.

\section{Seleção do sistema de irrigação de melhor retorno econômico}

Às vezes, tem-se a alternativa técnica de realizar a irrigação de uma mesma área com sistemas diferentes. No caso, é de particular interesse a escolha do sistema de irrigação mais adequado economicamente às condições específicas de produção da propriedade em questão. Uma maneira de se efetuar essa análise é executar o sistema computacional Tobruk com os dados dos sistemas de irrigação e escolher, então, aquele que fornece maior lucro com a lâmina ótima econômica de irrigação. Para exemplificar, considerou-se a possibilidade de irrigação com o sistema autopropelido, tipo carretel enrolador, a fim de compará-lo, em termos de desempenho econômico, com o pivô central instalado e definir qual dos dois é atualmente o melhor para a área com as considerações já assumidas. Assim, elaborou-se um projeto de autopropelido tipo carretel enrolador, aplicando-se a mesma lâmina líquida de $6,8 \mathrm{~mm} \mathrm{~d}^{-1}$, cujo orçamento é apresentado na Tabela 3. Neste, considerou-se uma lâmina bruta de $9,1 \mathrm{~mm}$ em um período de trabalho de $20 \mathrm{~h} \mathrm{~d}^{-1}$, solicitando uma potência líquida do motor de $90,91 \mathrm{~kW}$. Consideraram-se, ainda, as despesas com mão-de-obra e trator, necessários à operação do carretel enrolador, como sendo de $\mathrm{R} \$ 500,00$ mês $^{-1}$.

Tabela 3. Orçamento simplificado do sistema de irrigação por autopropelido, tipo carretel enrolador

\begin{tabular}{ll}
\hline Item & Valor $(\mathrm{R} \$)$ \\
\hline Conjunto motobomba & $32.998,00$ \\
Tubulação adutora e acessórios & $14.249,00$ \\
Carretel enrolador e acessórios & $46.743,00$ \\
Total & $93.990,00$ \\
\hline Fonte: Lavras Irrigação, fevereiro de 2001
\end{tabular}

Fonte: Lavras Irrigação, fevereiro de 2001

Com os referidos dados obteve-se, para o autopropelido irrigando o feijoeiro plantado em 4 de abril, a lâmina econômica ótima de 282,98 $\mathrm{mm}$, proporcionando um lucro total de $\mathrm{R} \$ 11.291,94$, para o valor da saca do feijão considerado em R\$ 80,00; já para o pivô central, encontrou-se lucro ótimo de $\mathrm{R} \$ 16.103,32$, para o mesmo valor de lâmina de irrigação, como apresentado anteriormente. Em vista desses resultados, observa-se que o sistema de irrigação por pivô central apresenta melhor desempenho econômico que o autopropelido sendo, portanto, economicamente mais adequado para a área, cultura, época e valores considerados.

A repetição dessa análise comparativa entre sistemas de irrigação, utilizando-se diversas culturas e seus respectivos métodos de produção, épocas de plantio e valores econômicos, auxiliaria os técnicos e produtores rurais na escolha do sistema de irrigação mais adequado economicamente à sua realidade local, uma vez que lhes apresentaria uma estimativa dos benefícios esperados com as diversas alternativas de sistemas de irrigação analisadas para a sua área específica. Desta forma, o Tobruk auxiliaria na escolha do sistema de irrigação que traga o melhor retorno econômico a curto, médio e longo prazos, sem que haja degradação do solo e do meio ambiente, uma exigência cada vez maior para a agricultura irrigada, como lembra Bernardo (1998).

\section{CONCLUSÕES}

1. O sistema computacional Tobruk constitui-se em uma opção que facilita e agiliza a determinação da lâmina ótima econômica de sistemas pressurizados de irrigação, permitindo ao usuário sua obtenção a partir do conhecimento das variáveis técnica-econômicas relacionadas ao objeto e sua forma de produção.

2. O programa pode ser utilizado como recurso auxiliar que facilita e agiliza a tomada de decisão em determinados problemas do planejamento da agricultura irrigada que envolva a maximização da rentabilidade da atividade associada ao uso racional dos recursos hídricos.

\section{LITERATURA CITADA}

Bernardo, S. Manual de irrigação. 5.ed. Viçosa: UFV, 1989. 596p. Bernardo, S. Irrigação e produtividade. In: Faria, M.A. de (coord). Manejo de irrigação. Poços de Caldas: SBEA/UFLA, 1998. p.117-132

Borg, H.; Grimes, D.W. Depth development of roots with time: An empirical description. Transactions of the ASAE, St. Joseph, v.29, n.1, p.194-197, 1986.

Bruxel, D. Debate. In: Encontro Mineiro de Irrigantes, 1, 1991, Belo Horizonte. Anais... Belo Horizonte: CEMIG, 1991, p.103-111

Cabello, F.P. Riegos localizados de alta frecuencia (RLAF): goteo, microaspersión, exudácion. 2.ed. rev. amp. Madrid: Mundi-Prensa, 1990.471p.

Castro, M.C. Sistema computacional para a determinação da lâmina econômica ótima em irrigação pressurizada. Lavras: UFLA, 2001. 137p. Dissertação Mestrado

Costa, M.H. Modelo de otimização dos recursos hídricos para irrigação, conforme a época de plantio. Viçosa: UFV, 1991. 111 p. Dissertação Mestrado

Dean, J. D. Modeling supplemental irrigation water demand. Journal of Irrigation and Drainage Division, New York, v.106, n.IR4, p.285-297, 1980

Doorenbos, J; Kassam, A.H. Efeitos da água no rendimento das culturas. Campina Grande: UFPB, 1994. 306p. Estudos FAO: Irrigação e Drenagem, 33 
Du Pont Produtos Agrícolas. Dossiê técnico sobre a cultura do feijão. São Paulo: 2000. 60p.

Felipe, M.P. Efeitos de diferentes lâminas de água e épocas de parcelamento da adubação nitrogenada na cultura do feijão (Phaseolus vulgaris L.). Lavras: ESAL, 1991. 105p. Dissertação Mestrado

Gonzaga Neto, L. Produtividade e competitividade dependem do aumento de hectares irrigados. Revista dos Agrônomos, São Paulo, v.3, n.1, p.14-20, 2000

Haan, C. T. Statistical methods in hydrology. Ames: Iowa State University Press, 1977.377p.

Jensen, M.E.; Burman, R.D.; Allen, R.G. (ed.) Evapotranspiration and irrigation water requirements. New York: ASCE, 1990. cap.5, p.60-79, ASCE Manuals and Reports on Engineering Practice, 70

Keller, J.; Bliesner, R.D. Sprinkle and trickle irrigation. New York: van Nostrand Reinhold, 1990. 652p.

Leme, E. E. de A.; Chaudhry, F. H. Uso de parâmetros meteorológicos na programação da irrigação. In: Congresso Brasileiro de Engenharia Agrícola, 21, 1992, Santa Maria. Anais... Santa Maria: SBEA, v.2a, 1992. p.754-773

McGuinness, J. L.; Parmele, L. H. Maximum potential evapotranspiration frequency-east central U.S. Journal of the Irrigation and Drainage Division, New York, v.98, n.IR2, p.207-214, 1972
Pereira, L.S.; Allen, R.G. Crop water requirements. In: Lier, N.V.(ed.) CIGR: Handbook of agricultural engineering. St. Joseph: ASAE, 1999. p.213-262. Land and Water Engineering, 1

Prajamwong, S.; Merkley, G. P.; Allen, R. G. Decision support model for irrigation water management. Journal of Irrigation and Drainage Engineering, New York, v.123, n.2, p.106-113, 1997.

Pruitt, W. O.; Oettingen, S. V.; Morgan, D. L. Central California evapotranspiration frequencies. Journal of the Irrigation and Drainage Division, New York, v.98, n.IR2 p.177-184, 1972

Silva, M.A.V.; Reis, A.C.S. Agrometeorologia e climatologia tropicais. Brasília: ABEAS, 1988. 90p. Curso de Especialização por Tutoria a Distância

Tomazela, C.; Scaloppi, E.J. Considerações técnicas e econômicas dos principais sistemas mecanizados de irrigação por aspersão. In: Congresso Nacional de Irrigação e Drenagem, 8, 1988, Florianópolis. Anais... Florianópolis: ABID, 1988. p.1233-1249

Tracy, J. C.; Marino, M. A. Management model for control of on-farm irrigation. Journal of Irrigation and Drainage Engineering, New York, v.115, n.6, p.954-972, 1989

Windsor, J. S.; Chow, V. T. Model for farm irrigation in humid areas. Journal of the Irrigation and Drainage Division, New York, v.97, n.IR3, p.369-385, 1971. 